\title{
An Encapsulated Fruit and Vegetable Juice Concentrate Increases Skin Microcirculation in Healthy Women
}

\author{
S. De Spirt ${ }^{a} \quad H$. Sies $^{a, b, d} \quad H$. Tronnier $^{c} \quad$ U. Heinrich ${ }^{c}$ \\ a Institute of Biochemistry and Molecular Biology I, Faculty of Medicine, and beibniz Research Institute for \\ Environmental Medicine, Heinrich Heine University, Düsseldorf, and 'Institute for Experimental Dermatology, \\ University of Witten-Herdecke, Witten, Germany; ${ }^{d}$ College of Science, King Saud University, Riyadh, Saudi Arabia
}

\section{Key Words}

Antioxidants $\cdot$ Vitamins $\cdot$ Microcirculation $\cdot$ Oxygen to see device

\begin{abstract}
Background/Aim: Microcirculation in the dermis of the skin is important for nutrient delivery to this tissue. In this study, the effects of a micronutrient concentrate (Juice Plus ${ }^{\circledR}{ }^{\circledR}$; 'active group'), composed primarily of fruit and vegetable juice powder, on skin microcirculation and structure were compared to placebo. Study Design/Methods: This 12-week study had a monocentric, double-blind placebo and randomized controlled design with two treatment groups consisting of 26 healthy middle-aged women each. The 'oxygen to see' device was used to evaluate microcirculation. Skin density and thickness were measured using ultrasound. Measurements for skin hydration (Corneometer ${ }^{\circledR}$ ), transepidermal water loss and serum analysis for carotenoids and $\alpha$-tocopherol were also performed. Results: By 12 weeks, microcirculation of the superficial plexus increased by $39 \%$. Furthermore, skin hydration increased by $9 \%$ while skin thickness increased by $6 \%$ and skin density by $16 \%$ in the active group. In the placebo group, microcirculation decreased,
\end{abstract}

and a slight increase in skin density was observed. Conclusion: Ingestion of a fruit- and vegetable-based concentrate increases microcirculation of the skin at 12 weeks of intervention and positively affects skin hydration, density and thickness.

Copyright $\odot 2011$ S. Karger AG, Basel

\section{Introduction}

Nutrition is an important factor in skin health. Studies have shown that nutritional deficiencies correlate with skin disorders and/or changes in skin physiology [1]. Next to fatty acids, micronutrients, like vitamins, carotenoids and polyphenols, are assumedly important active compounds in skin health [2]. Natural sources for these phytonutrients are fruits and vegetables. The effects are manifold, e.g. consumption of carotenoid-rich fruits and vegetables, or supplements, is known to improve skin photoprotection [3] or skin parameters such as structure or texture [4-8]. High-flavanol cocoa attenuated UV-induced erythema under experimental conditions [9]. Oxidation of proteins, DNA or lipids under UVA irradiation results in an increased cutaneous chemiluminescence

\section{KARGER}

Fax +4161306 1234 E-Mail karger@karger.ch www.karger.com (c) 2011 S. Karger AG, Basel

$1660-5527 / 12 / 0251-0002 \$ 38.00 / 0$

Accessible online at:

www.karger.com/spp
Prof. Ulrike Heinrich

Institute for Experimental Dermatology, University of Witten-Herdecke

Alfred-Herrhausen-Strasse 44

DE-58455 Witten (Germany)

Tel. +49 2302282 6300, E-Mail ulrike.heinrich@uni-wh.de 
signal, which was reduced by a topical application of an oil-in-water cream containing tocopheryl acetate, ferulic acid and rutin [10].

The biochemical mechanisms for these effects are not fully elucidated. The photoprotective effect is mainly based on the ability of these molecules to quench singlet oxygen or prevent oxidative damage induced by other reactive oxygen species [3]. Micronutrients can also influence cell signaling, with direct impact on intracellular and extracellular pathways, for example triggering cell cycle, cell growth or cellular repair systems $[11,12]$.

Nutritional support of the skin tissue is maintained by microcirculation. The blood vessels of the skin are arranged into (a) the superficial plexus, which is located 1-2 $\mathrm{mm}$ under the epidermis and is formed in capillary loops, and (b) the deeper horizontal plexus [13-15]. The tips of the capillary loops are mainly responsible for nutrition and oxygen exchange, along with thermoregulation [15].

In cosmetics research, the measurement of microcirculation is used to quantify sun protection factors, skin irritation and efficiency of antiredness treatments, because blood circulation influences skin color [13]. Such methods are further used to provide information on physiology and tissue nutrition [16] or to evaluate endothelial activity, because vasomotion of the microvessels is partially regulated by endothelial activity [17]. Altered skin endothelium-dependent vasomotion has been found in several chronic conditions, such as arterial hypertension, hypercholesterolemia, chronic kidney disease and in diabetes $[16,18]$.

The 'oxygen to see' device allows the simultaneous measurement of blood flow and oxygen saturation $\left(\mathrm{SO}_{2}\right)$ of hemoglobin. This method is commonly used and well validated for monitoring microcirculation in diabetics, in whom changes in skin microcirculation have been found to occur years prior to microvascular symptoms in other tissues [16].

The aim of this study was to evaluate the effect of a micronutrient concentrate composed primarily of fruit and vegetable juice powder on skin microcirculation and structure, compared to placebo.

\section{Subjects and Methods}

\section{Study Design}

This was a monocentric, randomized, double-blind placebocontrolled study of 52 healthy women with normal to dry skin, aged 40-65 years, and a BMI of 18-25 who were recruited by the Institute for Experimental Dermatology (DermaTronnier ${ }^{\circledR}$ ), University of Witten-Herdecke, Germany. All volunteers were screened for general health and medical history, and only those who were nonsmokers, not pregnant or lactating and had no history of nutrient malabsorption, liver or lipid abnormalities and no history of photosensitizing disorders were eligible to enter the investigation. Use of nutritional supplements, tanning beds, sunbathing or medications that interact or interfere with the study procedures were not allowed for a month prior to and during the study.

The volunteers ingested 4 capsules of the active agent (Juice Plus $+{ }^{\circledR}$ Fruit Blend and Vegetable Blend; NSA, Collierville, Tenn., USA) or placebo daily, 2 in the morning and 2 in the evening.

The active gelatin capsule contents consisted primarily of a blended fruit and vegetable pulp and juice powder concentrate derived from acerola cherry, apple, beet, beetroot, broccoli, cabbage, carrot, cranberry, dates, garlic, kale, orange, peach, papaya, parsley, pineapple, prune, spinach, sugar beet, tomato, with Spirulina pacifica, Lactobacillus acidophilus, rice bran, oat bran and Dunaliella salina. These active ingredients provided $\beta$-carotene (7.5 mg), vitamin E (46 mg), vitamin C (200 mg) and folic acid $(400 \mu \mathrm{g})$ per 4 capsules, i.e. the daily dose [19]. Small quantities of anticaking agents (calcium carbonate, magnesium oxide, magnesium stearate, cellulose) and thickeners (citrus pectin, guar gum) are added manufacturing aids.

The placebo capsules were identical in appearance and contained no antioxidants, consisting primarily of microcrystalline cellulose. All study capsules were provided by NSA. This 12-week study was carried out between October and February. Skin parameters were determined and blood samples collected at baseline (week 0) and at study weeks 6 and 12 .

Written informed consent was obtained from each participant. The study design was approved by the Ethics Committee of the University of Witten-Herdecke, Germany; it was performed according to the Good Clinical Practice guidelines and the Declaration of Helsinki.

Chemicals and Reagents

Reagents were from Merck (Darmstadt, Germany) unless stated otherwise.

\section{Skin Measurements}

All skin measurements were performed on the inner forearm under consistent room temperature and humidity. No topical treatment was allowed in this area during the study.

Cutaneous Blood Flow and Oxygen Saturation of Hemoglobin

The 'oxygen to see' system (Lea Instruments, Giessen, Germany) was used to determine cutaneous blood flow. The measurement is based on the laser Doppler effect, which is triggered by movement of the erythrocytes. Results are given in arbitrary units. Capillary $\mathrm{SO}_{2}$ was determined spectroscopically and given as percent of total hemoglobin. Both parameters were determined at 1 and $8 \mathrm{~mm}$ below the skin surface $[16,20]$ and were performed according to the Guidance of the European Expert Group on Efficacy Measurement of Cosmetics and Other Topical Products [13]. Measurement at $1 \mathrm{~mm}$ reflects the microcirculation of the skin, whereas at $8 \mathrm{~mm}$ the general blood circulation is detected. The latter was conducted as control measurement.

Ultrasound Measurements (B Scan)

Skin density and thickness (dermis and epidermis) was measured using an ultrasound device (B scan) with a frequency of 20 
Table 1. Skin parameters after ingestion of a fruit- and vegetable-based concentrate (active) compared to placebo

\begin{tabular}{|c|c|c|c|c|c|c|}
\hline \multirow[t]{2}{*}{ Skin parameter } & \multicolumn{3}{|c|}{ Active group } & \multicolumn{3}{|c|}{ Placebo group } \\
\hline & week 0 & week 6 & week 12 & week 0 & week 6 & week 12 \\
\hline Blood flow at $1 \mathrm{~mm}, \mathrm{AU}$ & $6.6 \pm 2.4$ & $8.0 \pm 3.7$ & $9.2 \pm 4.1^{*}$ & $8.4 \pm 3.6$ & $7.3 \pm 3.7$ & $5.8 \pm 2.9^{*}$ \\
\hline $\mathrm{SO}_{2}$ at $1 \mathrm{~mm}, \%$ & $46.7 \pm 12.1$ & $53.7 \pm 14.6^{*}$ & $54.3 \pm 12.5^{*}$ & $54.3 \pm 12.3$ & $50.0 \pm 13.2$ & $48.6 \pm 11.6$ \\
\hline Blood flow at $8 \mathrm{~mm}, \mathrm{AU}$ & $117 \pm 40.5$ & $122 \pm 51.5$ & $136 \pm 44.8$ & $142 \pm 41.9$ & $120 \pm 37.3^{*}$ & $106 \pm 40.9^{*}$ \\
\hline $\mathrm{SO}_{2}$ at $8 \mathrm{~mm}, \%$ & $71.3 \pm 14.0$ & $70.3 \pm 7.9$ & $72.7 \pm 10.3$ & $74.0 \pm 10.1$ & $69.5 \pm 9.5^{*}$ & $72.1 \pm 8.6$ \\
\hline Hydration, AU & $35.9 \pm 7.79$ & $37.5 \pm 7.65$ & $39.3 \pm 7.65^{*}$ & $29.8 \pm 6.05$ & $28.2 \pm 6.03$ & $30.4 \pm 5.39$ \\
\hline TEWL, $\mathrm{g} \mathrm{h}^{-1} \mathrm{~m}^{-2}$ & $8.1 \pm 2.60$ & $7.4 \pm 1.66$ & $7.6 \pm 1.66$ & $7.2 \pm 1.85$ & $7.8 \pm 1.49$ & $7.7 \pm 1.86$ \\
\hline Skin thickness, mm & $1.17 \pm 0.14$ & $1.16 \pm 0.28$ & $1.24 \pm 0.17^{*}$ & $1.16 \pm 0.10$ & $1.17 \pm 0.09$ & $1.14 \pm 0.12$ \\
\hline Skin density, mm² & $6.65 \pm 0.88$ & $7.20 \pm 1.08^{*}$ & $7.73 \pm 0.95^{*}$ & $6.40 \pm 0.85$ & $6.74 \pm 0.75^{*}$ & $6.88 \pm 0.86^{*}$ \\
\hline
\end{tabular}

${ }^{*} \mathrm{p}<$ 0.05: significantly different from week 0 . Data are given as means $\pm \mathrm{SD} ; \mathrm{n}=26$ /group. AU $=$ Arbitrary units.

MHz (Derma Scan C, with 2-dimensional configuration; Cortex Technology, Denmark). Density is given by pixel density in the measured area (square millimeters); thickness is measured in millimeters [21].

\section{Skin Hydration and Transepidermal Water Loss}

The determination of the skin hydration is based on capacitance measurement of a dielectric medium with a Corneometer CM $825^{\circledR}$ (Courage \& Khazaka Electronics, Cologne, Germany) expressed in arbitrary units [22]. Transepidermal water loss (TEWL) was measured with a Tewameter TM $300{ }^{\circledR}$ (Courage \& Khazaka Electronics) and is expressed in grams per hour per square meter [23].

All skin measurements were performed according to the European Cosmetic Associations Guidelines [24].

\section{Serum Analysis}

Serum was prepared from whole-blood samples by centrifugation without anticoagulant and stored at $-80^{\circ} \mathrm{C}$ until analysis. Carotenoids were determined by HPLC using a Merck-Hitachi (Darmstadt, Germany) L-7100 pump connected with a MerckHitachi UV/Vis detector [25]. Serum samples were extracted with $\mathrm{n}$-hexane/dichloromethane (5/1 vol/vol, $0.01 \%$ butylated hydroxytoluene). The organic layer was removed and evaporated to dryness under a stream of nitrogen. The residue was dissolved in dichloromethane/mobile phase (1/10 vol/vol). Chromatograms were processed by a HPLC System Manager HSM D-7000 (MerckHitachi). HPLC was performed isocratically with a mobile phase containing methanol/acetonitrile/propanol (54/44/2 vol/vol/vol) and using a reversed-phase column (pKb-100, $250 \times 4.6 \mathrm{~mm}$; Supelco, Bellefonte, Pa., USA), protected by a guard column $(4.6 \times$ $4.6 \mathrm{~mm}^{2}$ ) with the same stationary phase. The flow rate was set to $1 \mathrm{ml} \mathrm{min}{ }^{-1}$. Carotenoids were detected at $450 \mathrm{~nm}$.

Retinol and $\alpha$-tocopherol were extracted and detected simultaneously, the UV/Vis detector was set at $292 \mathrm{~nm}$ and $325 \mathrm{~nm}$ [26].

The concentrations of the analytes were calculated from external calibration curves generated with original standard compounds and internal standards. Data are given in micromoles per liter.
Table 2. $p$ values of skin parameters (table 1 ) for the comparison between groups using the Wilcoxon rank sum test

\begin{tabular}{lll}
\hline Skin parameter & \multicolumn{2}{l}{ p values } \\
\cline { 2 - 3 } & week 6 vs. 0 & week 12 vs. 0 \\
\hline Blood flow at $1 \mathrm{~mm}$ & 0.0288 & $<0.0001$ \\
$\mathrm{SO}_{2}$ at $1 \mathrm{~mm}$ & 0.0006 & 0.0001 \\
$\mathrm{Blood} \mathrm{flow} \mathrm{at} 8 \mathrm{~mm}_{\mathrm{SO}_{2} \text { at } 8 \mathrm{~mm}}$ & 0.0182 & $<0.0001$ \\
$\mathrm{Hydration}$ & n.s. & n.s. \\
TEWL & n.s. & n.s. \\
Skin thickness & n.s. & n.s. \\
Skin density & n.s. & 0.0143 \\
\hline
\end{tabular}

\section{Statistics}

All data are given as means \pm SD. For all parameters and all time points, descriptive statistics were calculated, pre-post differences were calculated and analyzed descriptively. Within the two treatment groups, each combination of two points of time was compared using the nonparametric Wilcoxon signed-rank test. For the pre-post differences, each combination of two treatment groups was compared using the Wilcoxon rank sum test. $p$ Values were determined at all measuring points with $p<0.05$ considered statistically significant.

\section{Results}

\section{Cutaneous Blood Flow and $\mathrm{SO}_{2}$}

Cutaneous blood flow and capillary $\mathrm{SO}_{2}$ of hemoglobin were measured at 1 and $8 \mathrm{~mm}$ under the skin surface. Blood flow at $1 \mathrm{~mm}$ depth was increased by $21 \%$ after 6 weeks and statistically significant by $39 \%$ after 12 weeks compared to week 0 ( $\mathrm{p}=0.003$; table 1 , fig. 1$)$ in the active 

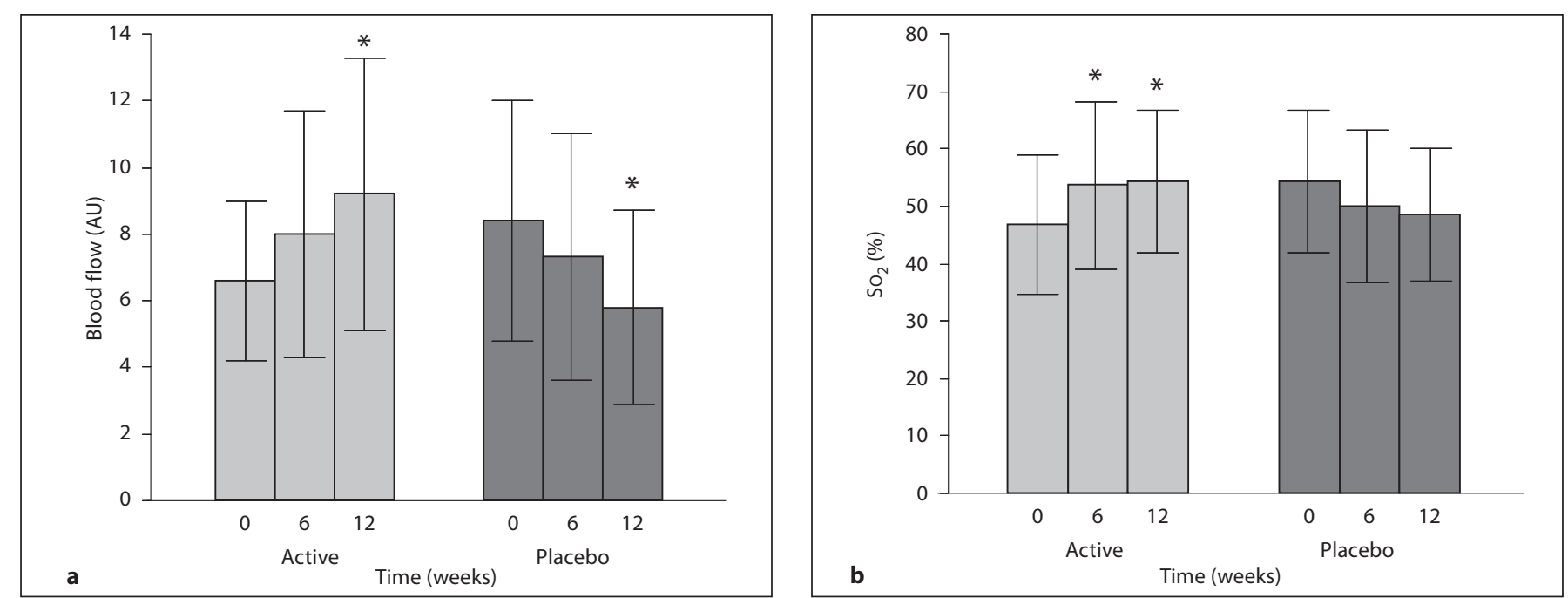

Fig. 1. Blood flow (a) in arbitrary units $(\mathrm{AU})$ and $\mathrm{SO}_{2}(\mathbf{b})$ at $1 \mathrm{~mm}$ skin depth after ingestion of the fruit- and vegetable-based concentrate (active) or placebo. Data are given as means $\pm \mathrm{SD} ; \mathrm{n}=26$ /group. ${ }^{*} \mathrm{p}<0.05$ : significantly different from week 0 .

group. $\mathrm{SO}_{2}$ also increased significantly by $15 \%$ after 6 weeks compared to week 0 in the active group $(\mathrm{p}=0.004)$, while the difference between week 6 and week 12 was only $1 \%$. In contrast, the placebo group showed a statistically significant decrease in blood flow after 12 weeks $(-31 \%$, $\mathrm{p}=0.001)$ compared to week 0 . For both parameters at $1 \mathrm{~mm}$ depth, the comparison of the pre-post differences 'week 6 - week 0 ' and 'week 12 - week 0 ' showed a statistically significant difference in favor of the active group (table 2).

At $8 \mathrm{~mm}$ depth, neither blood flow nor $\mathrm{SO}_{2}$ were changed significantly in the active group (table 1). In the placebo group blood flow decreased statistically significantly by -15 and $-25 \%$ after 6 weeks $(\mathrm{p}=0.005)$ and 12 weeks ( $\mathrm{p}<0.0001)$, respectively, compared to week 0 . Also the $\mathrm{SO}_{2}$ was decreased, but only significantly after 6 weeks $(-6 \%, \mathrm{p}=0.01)$.

The parameter blood flow showed statistically significant pre-post differences between groups in favor of the active capsules for both time differences at $1 \mathrm{~mm}$ (table 2). Due to the reduction of blood flow at $8 \mathrm{~mm}$ in the placebo group, the comparison of the pre-post-difference was statistically significant, too.

\section{Ultrasound Measurements (B Scan)}

The skin ultrasound measurement showed increased skin thickness and skin density in the active group. Skin thickness increased by $6 \%(\mathrm{p}=0.007)$, skin density by $16 \%$ after 12 weeks ( $<<0.0001$; table 1$)$. In the placebo group only the density of the skin increased significantly by $7 \%(\mathrm{p}=0.036)$. The $\mathrm{p}$ values for the comparison between the groups showed that the increase in thickness and density were statistically significant between weeks 12 and 0 in favor of the active group (table 2). A typical ultrasound B scan is presented in figure 2. It shows the density and thickness of the dermis before and after 12 weeks of treatment for a volunteer from the active group.

\section{Skin Hydration and TEWL}

In the active group skin hydration showed an increase of $9 \%$ after 12 weeks $(p=0.014)$. The placebo group showed no change.

A decrease in the TEWL was observed in the active group, with $-9 \%$ after 6 weeks and $-6 \%$ after 12 weeks compared to baseline; these changes were not statistically significant. The TEWL in the placebo group increased, but not statistically significantly either. The pre-post difference comparison of active versus placebo groups showed no difference in hydration and TEWL.

\section{Serum Analysis}

Carotenoid analysis showed a significant increase from baseline in $\beta$-carotene and $\alpha$-tocopherol $(\mathrm{p}<0.0001$, week 6 and 12) in the active group, while no change was observed in the placebo group (table 3). Both groups showed a significant increase in $\beta$-cryptoxanthin during the study period. 

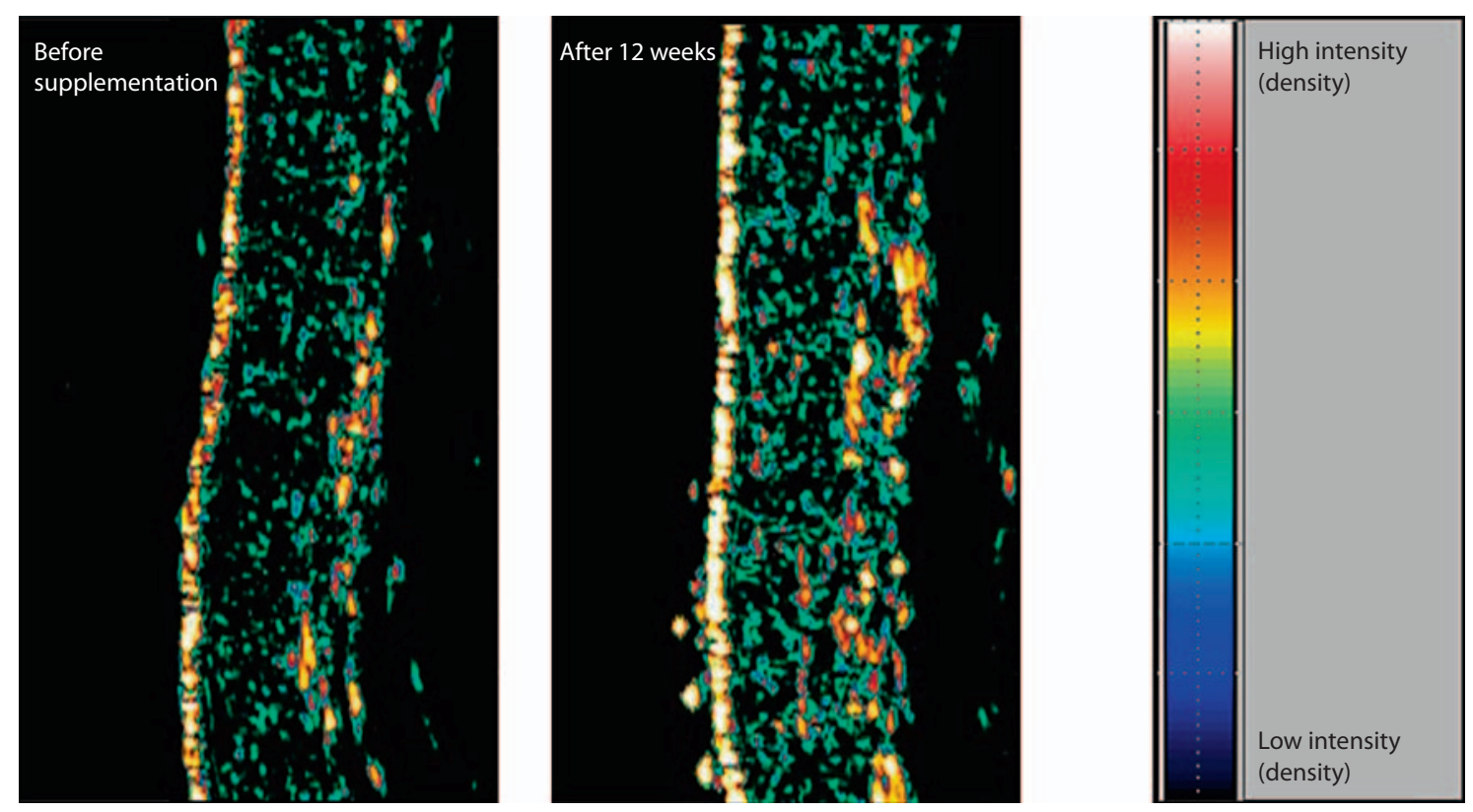

Fig. 2. A typical ultrasound B scan of the epidermis and dermis showing the density and thickness, before and after 12 weeks of treatment of the fruit- and vegetable-based concentrate (active).

Table 3. Serum levels of carotenoids, $\alpha$-tocopherol and retinol $\left(\mu \mathrm{moll}^{-1}\right)$ after ingestion of a fruit- and vegetablebased concentrate (active) compared to placebo

\begin{tabular}{|c|c|c|c|c|c|c|}
\hline \multirow[t]{2}{*}{ Substance } & \multicolumn{3}{|c|}{ Active group } & \multicolumn{3}{|c|}{ Placebo group } \\
\hline & week 0 & week 6 & week 12 & week 0 & week 6 & week 12 \\
\hline Lutein & $0.27 \pm 0.10$ & $0.27 \pm 0.08$ & $0.27 \pm 0.09$ & $0.30 \pm 0.11$ & $0.31 \pm 0.12$ & $0.31 \pm 0.11$ \\
\hline Zeaxanthin & $0.08 \pm 0.03$ & $0.09 \pm 0.03$ & $0.09 \pm 0.03$ & $0.10 \pm 0.04$ & $0.10 \pm 0.04$ & $0.10 \pm 0.03$ \\
\hline Cryptoxanthin & $0.23 \pm 0.11$ & $0.38 \pm 0.33^{*}$ & $0.48 \pm 0.31^{*}$ & $0.27 \pm 0.10$ & $0.40 \pm 0.21^{*}$ & $0.40 \pm 0.23^{*}$ \\
\hline Lycopene & $0.62 \pm 0.30$ & $0.59 \pm 0.33$ & $0.55 \pm 0.30$ & $0.69 \pm 0.37$ & $0.70 \pm 0.35$ & $0.65 \pm 0.42$ \\
\hline$\alpha$-Carotene & $0.17 \pm 0.18$ & $0.15 \pm 0.12$ & $0.15 \pm 0.10$ & $0.15 \pm 0.10$ & $0.15 \pm 0.11$ & $0.14 \pm 0.10$ \\
\hline$\beta$-Carotene & $0.88 \pm 0.74$ & $2.44 \pm 1.27^{*}$ & $2.55 \pm 1.40^{*}$ & $0.68 \pm 0.34$ & $0.71 \pm 0.41$ & $0.65 \pm 0.34$ \\
\hline$\alpha$-Tocopherol & $23.4 \pm 6.0$ & $27.4 \pm 5.6^{*}$ & $27.5 \pm 7.3^{*}$ & $21.8 \pm 5.1$ & $20.2 \pm 4.1$ & $21.8 \pm 4.7$ \\
\hline Retinol & $1.23 \pm 0.27$ & $1.23 \pm 0.27$ & $1.19 \pm 0.28$ & $1.20 \pm 0.35$ & $1.12 \pm 0.35$ & $1.12 \pm 0.30$ \\
\hline
\end{tabular}

${ }^{*} \mathrm{p}<0.05$ : significantly different from week 0 . Data are given as means $\pm \mathrm{SD} ; \mathrm{n}=26 /$ group. The comparison of the pre-post differences showed significant differences in favor of the active group for $\beta$-carotene $(\mathrm{p}<0.0001$ week 6 vs. 0 and week 12 vs. 0$)$ and for $\alpha$-tocopherol ( $<<0.0001$ week 6 vs. $0, p=0.0004$ week 12 vs. 0 ).

\section{Discussion}

Skin microcirculation is responsible for nutrition, oxygen supply and thermoregulation [14]. An optimal supply of the skin with nutrients and oxygen is necessary for skin cell metabolism, therefore supporting skin physiology, structure and health [4-8]. The question in the pres- ent study was whether an encapsulated fruit- and vegetable-based juice powder concentrate (Juice Plus+) could modulate skin microcirculation and structure. The major micronutrients in the active capsules were $\beta$-carotene, vitamin E, vitamin C and folate. HPLC measurement showed an increase in $\beta$-carotene and vitamin $\mathrm{E}$ serum levels (table 3 ). In a study using a similar concentrate, 
plasma vitamin $C$ levels increased as well as $\beta$-carotene and vitamin $\mathrm{E}$ [19]. In the present study $\beta$-cryptoxanthin increased in both groups. Oranges and tangerines are natural sources of $\beta$-cryptoxanthin [27], typical fruits consumed during winter, when this study was conducted.

Microcirculation was measured with the 'oxygen to see' device. In the active group, blood flow and $\mathrm{SO}_{2}$ increased at $1 \mathrm{~mm}$ skin depth. At $8 \mathrm{~mm}$ only minor changes were observed. These data indicate that the microcirculation of the superficial plexus was affected more than the general circulation, because the superficial vessels are surrounded by only 1-2 layers of smooth muscle cells [14]. Thinner vessels may react faster or be more sensitive to micronutrients than thicker, deeper vessels. Because of this, the skin could be supplied with oxygen and nutrients more readily, perhaps without affecting the general circulation. However, in a study with high flavanol cocoa, the deeper vessels responded with an increase in blood flow [9]. Increasing blood flow results from vasodilation of the blood vessels. Nitric oxide is one key regulator of blood vasodilation affecting the surrounding smooth muscle cells of the endothelium [21,28]. Antioxidants, folate and a greater intake of fruit and vegetables showed beneficial effects on endothelium-dependent vasoconstriction $[29,30]$.

With better supply of nutrients and oxygen essential for skin metabolism, skin function, texture and structure can be improved [4-8]. Change in the skin texture is a result of loss in barrier integrity [31]. This again can result in increased TEWL and diminished skin hydration. During the study TEWL was slightly decreased and skin hy- dration was increased; thus, there was a small but positive effect on skin barrier function of the stratum corneum.

Additionally, deeper skin levels of epidermis and dermis were affected. It is known that skin density and thickness decrease during the aging process [32]. It is unknown if this process can be counteracted by micronutrients, but intervention of 12 weeks was sufficient to improve thickness and density (table 1) in this study. A similar study, using a supplement mixture of carotenoids, vitamin $\mathrm{E}$ and selenium, showed an increase in these skin parameters as well [5].

In conclusion, the present study shows that intake of a fruit- and vegetable-based concentrate increases skin microcirculation and improves skin texture and structure compared to placebo.

\section{Acknowledgements}

The authors thank Mrs. M. Wiebusch and Mrs. H. Krahl for assistance and Mrs. Dipl. Stat. A. Grieger for statistical consulting and evaluation of the data, and all the volunteers who made this investigation possible. H.S. is a Fellow of the National Foundation for Cancer Research (NFCR), Bethesda, Md., USA. The research was sponsored in part by a grant from NSA LLC, Collierville, Tenn., USA. The sponsor participated in the discussion of the study design and provided the study capsules.

\section{Disclosure Statement}

The authors declare no conflict of interest.

\section{References}

1 Piccardi N, Manissier P: Nutrition and nutritional supplementation: impact on skin health and beauty. Dermatoendocrinol 2009; 1:271-274.

$\checkmark 2$ Boelsma E, Hendriks HF, Roza L: Nutritional skin care: health effects of micronutrients and fatty acids. Am J Clin Nutr 2001;73:853864.

-3 Sies H, Stahl W: Nutritional protection against skin damage from sunlight. Annu Rev Nutr 2004;24:173-200.

4 Udompataikul M, Sripiroj P, Palungwachira P: An oral nutraceutical containing antioxidants, minerals and glycosaminoglycans improves skin roughness and fine wrinkles. Int J Cosmet Sci 2009;31:427-435.

5 Heinrich U, Tronnier H, Stahl W, Béjot M, Maurette JM: Antioxidant supplements improve parameters related to skin structure in humans. Skin Pharmacol Physiol 2006;19: 224-231.

\footnotetext{
-6 Boelsma E, van de Vijver LP, Goldbohm RA, 10 Jain A, Rieger I, Rohr M, Schrader A: AntiKlöpping-Ketelaars IA, Hendriks HF, Roza oxidant efficacy on human skin in vivo inL: Human skin condition and its associations vestigated by UVA-induced chemilumineswith nutrient concentrations in serum and cence decay analysis via induced chemilumidiet. Am J Clin Nutr 2003;77:348-355.

7 Darvin M, Patzelt A, Gehse S, Schanzer S, Benderoth C, Sterry W, Lademann J: Cutaneous concentration of lycopene correlates significantly with the roughness of the skin. Eur J Pharm Biopharm 2008;69:943-947.

$\checkmark 8$ Jeon HY, Kim JK, Seo DB, Cho SY, Lee SJ: Beneficial effect of dietary epigallocatechin3 -gallate on skin via enhancement of antioxidant capacity in both blood and skin. Skin Pharmacol Physiol 2010;23:283-289.

$\checkmark 9$ Heinrich U, Neukam K, Tronnier H, Sies H, Stahl W: Long-term ingestion of high flavanol cocoa provides photoprotection against UV-induced erythema and improves skin condition in women. J Nutr 2006;136:1565nescence of human skin. Skin Pharmacol Physiol 2010;23:266-272.

11 Brigelius-Flohé R, Banning A: Sulforaphane and selenium, partners in adaptive response and prevention of cancer. Free Radic Res 2006;40:775-787.

12 Stahl W, Ale-Agha N, Polidori MC: Non-antioxidant properties of carotenoids. Biol Chem 2002;383:553-558.

13 Berardesca E, Lévêque JL, Masson P: EEM$\mathrm{CO}$ guidance for the measurement of skin microcirculation. Skin Pharmacol Appl Skin Physiol 2002;15:442-456.

14 Braverman IM: The cutaneous microcirculation. J Investig Dermatol Symp Proc 2000; $5: 3-9$.
} 1569. 
-15 Wright CI, Kroner CI, Draijer R: Non-invasive methods and stimuli for evaluating the skin's microcirculation. J Pharmacol Toxicol Methods 2006;54:1-25.

16 Forst T, Hohberg C, Tarakci E, Forst S, Kann P, Pfützner A: Reliability of lightguide spectrophotometry $(\mathrm{O} 2 \mathrm{C})$ for the investigation of skin tissue microvascular blood flow and tissue oxygen supply in diabetic and nondiabetic subjects. J Diabetes Sci Technol 2008;2: 1151-1156.

- 17 Rossi M, Carpi A, Galetta F, Franzoni F, Santoro G: Skin vasomotion investigation: a useful tool for clinical evaluation of microvascular endothelial function? Biomed Pharmacother 2008;62:541-545.

-18 Rossi M, Carpi A, Di Maria C, Franzoni F, Galetta F, Santoro G: Skin blood flowmotion and microvascular reactivity investigation in hypercholesterolemic patients without clinically manifest arterial diseases. Physiol Res 2009;58:39-47.

-19 Jin Y, Cui X, Singh UP, Chumanevich AA, Harmon B, Cavicchia P, Hofseth AB, Kotakadi V, Stroud B, Volate SR, Hurley TG, Hebert JR, Hofseth LJ: Systemic inflammatory load in humans is suppressed by consumption of two formulations of dried, encapsulated juice concentrate. Mol Nutr Food Res 2010;54:1506-1514.
20 Krug A: Mikrozirkulation und Sauerstoffversorgung des Gewebes - Methode des so genannten $\mathrm{O} 2 \mathrm{C}$ (oxygen to see). Phlebologie 2006;35:300-312.

21 Neukam K, Stahl W, Tronnier H, Sies H, Heinrich U: Consumption of flavanol-rich cocoa acutely increases microcirculation in human skin. Eur J Nutr 2007;46:53-56.

22 Heinrich U, Koop U, Leneveu-Duchemin MC, Osterrieder K, Bielfeldt S, Chkarnat C, Degwert J, Häntschel D, Jaspers S, Nissen HP, Rohr M, Schneider G, Tronnier H: Multicentre comparison of skin hydration in terms of physical-, physiological- and product-dependent parameters by the capacitive method (Corneometer CM 825). Int J Cosmet Sci 2003;25:45-53.

23 Rodrigues LM, Pinto PC, Magro JM, Fernandes M, Alves J: Exploring the influence of skin perfusion on transepidermal water loss. Skin Res Technol 2004;10:257-262.

24 Colipa (European Cosmetic Association): Guideline for the evaluation of the efficacy of cosmetic products. 2008. http://www.colipa. eu.

25 Stahl W, Sundquist AR, Hanusch M, Schwarz W, Sies H: Separation of beta-carotene and lycopene geometrical isomers in biological samples. Clin Chem 1993;39:810-814.

-26 Polidori MC, Stahl W, Eichler O, Niestroj I, Sies H: Profiles of antioxidants in human plasma. Free Radic Biol Med 2001;30:456462 .
27 Mangels AR, Holden JM, Beecher GR, Foreman MR, Lanza E: Carotenoid content of fruits and vegetables: an evaluation of analytical data. J Am Diet Assoc 1993;93:284296.

28 Heiss C, Schroeter H, Balzer J, Kleinbongard P, Matern S, Sies H, Kelm M: Endothelial function, nitric oxide, and cocoa flavanols. J Cardiovasc Pharmacol 2006; 47(suppl 2):128-135.

29 Brown AA, Hu FB: Dietary modulation of endothelial function: implications for cardiovascular disease. Am J Clin Nutr 2001;73: 673-686.

30 McCall DO, McGartland CP, McKinley MC, Patterson CC, Sharpe P, McCance DR, Young IS, Woodside JV: Dietary intake of fruits and vegetables improves microvascular function in hypertensive subjects in a dose-dependent manner. Circulation 2009; 119:2153-2160.

-31 Callaghan TM, Wilhelm KP: A review of ageing and an examination of clinical methods in the assessment of ageing skin. 2. Clinical perspectives and clinical methods in the evaluation of ageing skin. Int J Cosmet Sci 2008;30:323-332.

32 Waller JM, Maibach HI: Age and skin structure and function, a quantitative approach. I. Blood flow, pH, thickness, and ultrasound echogenicity. Skin Res Technol 2005;11:221235 . 